\title{
UKRN Position on Academic Publishing
}

The UK Reproducibility Network Steering Group

$1^{\text {st }}$ June 2021

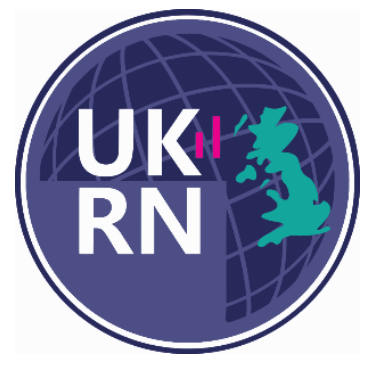

The UK higher education sector has invested approximately $£ 1 \mathrm{bn}$ in academic publishing over the last decade ${ }^{1}$. In our view, the principles guiding interactions between UK institutions and academic publishers should be:

1. Value for money.

2. Availability of output to all readers without subscription (e.g., open licensing).

3. Transparency in agreements (e.g., making costs openly available).

4. Support for and implementation of initiatives such as DORA.

5. Support for transparent research practices (e.g., around data and code).

6. Support for text and data mining (at no extra cost).

7. Active and transparent engagement with expressions of concern.

The UK higher education sector should take these factors into account in discussions with academic publishers, on the understanding that our continuing support of those who do not meet an acceptable standard is not in the long-term interests of the sector.

${ }^{1}$ https://www.timeshighereducation.com/news/uk-universities-paid-big-publishers-ps 1 billionpast-decade

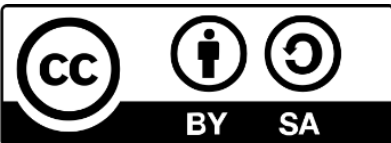

This work is licensed under a Creative Commons Attribution-ShareAlike 4.0 International License. 